\title{
A Feminist Analysis of Anti-Obesity Campaigns: \\ Manipulation, Oppression, and Autonomy \\ Kathryn MacKay
}

\begin{abstract}
Some kinds of public health messages are unjust and unethical, and feminist analyses of oppression and autonomy can assist in explaining why. Using public health anti-obesity campaigns to provide context, I explore, in this paper, how manipulative public health campaigns oppress the targets of these messages, and undermine people's ability to be self-directed decision makers. I begin with an analysis of what it means to communicate in a manipulative way. This leads to the argument that such campaigns are both oppressive and incompatible with the self-authorization required for health-related behavioral changes.
\end{abstract}

Keywords: fat shaming, manipulation and oppression, self-authorization, public health obesity campaigns

\section{Introduction}

A few years ago, the New York City Department of Health introduced a public health campaign entitled "Cut Your Portions, Cut Your Risk" (New York City Department of Health and Mental Hygiene [NYC DOH MH] 2012), a series of posters in which images of food in increasingly large portion sizes appear. In one example, three packets of french fries are featured; in another, cheeseburgers are shown. In a red box in each, the text, in large, all-capital letters in English and Spanish, reads "Portions have grown," and, below this, in all capitals, "so has obesity, which can lead to many health problems" or "so has type 2 
diabetes, which can lead to amputations." Beneath the food, the posters admonish, again in all-capital letters, "Cut your portions. Cut your risk."

Above this text in two of these posters are black-and-white images of fat women. In the poster featuring cheeseburgers, the woman is crossing the street on a mobility scooter, appears only from the nose down, and is wearing a t-shirt and jeans. In the poster featuring french fries, the woman is climbing a staircase. Her hair is pulled back, she is wearing a white sweater and black trousers, and she is carrying a purse on one shoulder and a bag in one hand. Her free hand grips the railing, and her elbow is bent. Her left leg is also bent as she takes a new stair. In a third poster, a fat man sits on a stool, his right leg amputated below the knee.

This poster series is just one of many examples of public health anti-obesity campaigns from around the world, and is presented here to provide context for the issues that I discuss in this paper. Some features of these posters make them particularly suited to illustrative purposes. For example, in the french fries poster, the woman's pose could make her appear to be laboring to climb the staircase, with bent elbow and drooping head, hauling her body upwards, and it seems from the context of the poster that this is either what the creators saw or intended others to see, and perhaps both. However, on looking carefully, one can see that the woman is taking the stairs two-at-a-time, with her forward foot two stairs ahead of her back foot. Rather than making the climb look like a difficult task, the pose could be one of speed: the woman has her head down, elbows bent, and is running up the stairs. The creators of the poster may have intended that she appear to be struggling, but she could simply be hurrying. The image of the woman on the mobility scooter and the man on the stool both seem to imply that body fat led these people to states of physical impairment. This highlights an important, current, and deeply-held assumption 
common in many countries: that fat people are not (and cannot be) fit. As such, the woman could not run up the flight of stairs, and the woman in the cheeseburger poster must use the mobility scooter because of her weight. The assumption that a person's outward appearance is a reliable indicator of internal health states and characteristics is currently pervasive in both advanced democratic nations and nations with emerging economies.

Additionally, in all three posters, the individuals' faces are obscured. The woman on the scooter and the man on the stool are portrayed from their noses down, and the person on the stairs has her face turned away from the camera. This is a common way of depicting fat people in campaigns, and demonstrates reluctance among the people designing them to associate a person's unique identity with the body image used to illustrate a message. This kind of portrayal of fat people, along with people with stigmatized illnesses, has been described as the visualization of shame (Heuer et al. 2011). As I will argue below, it communicates that fat people should feel shame about their bodies, and has important repercussions for the development of the self-regarding attitudes required for autonomy.

These depictions, as well as other examples, will be employed as illustrations of ethical problems that appear in public health messages of many different kinds. While using anti-obesity campaigns as the context for this discussion, many of the problems apparent in them are also present in other kinds of campaigns (such as antismoking, antidrug, and antialcohol campaigns). Throughout this paper, when using the term "obesity," I will be referring specifically to the medicalized notion of body fat as a disease state, and with reference to the way that public health and medicine conceive of fatness. When describing people, however, I will use the term "fat" as a straightforward and nonjudgmental descriptor of a body. Just as only some thin bodies are healthy bodies, only some fat bodies are unhealthy bodies. Fat is an essential part of every body. In what follows, I argue that 
certain public health messages are manipulative, and that campaigns that employ manipulative communication oppress the targets of their messages, undermining people's ability to be self-directed decision makers. Such campaigns are, thus, unethical and ineffective.

\section{MANIPULATION}

To begin, it is important to discuss what I mean by manipulation. Many public health campaigns - including those with an anti-obesity focus - employ methods of communication that can be considered manipulative. In examining the kind of communication that takes place in them, I turn to Neil Manson and Onora O’Neill's (2007) analysis of informing, because I take the friendly view that, most of the time, public health practitioners designing campaigns imagine themselves engaged in informing a particular audience about a particular thing.

Manson and O'Neill describe the communicative process involved in informing as a type of action, which they call the "agency model of communication." As opposed to the conduit metaphor of communication, which supposes communication to be the transfer of meaning, ideas, or content in chunks (like bytes) from one person to another, the agency model of informing views information as the content of communicative transactions speech acts, behavioral cues, gestures, and so on - which succeed only where participants acknowledge each other as agents with cognitive and practical commitments, and assume one another's adherence to a range of communicative, epistemic, and ethical norms. On this view, communication is a normatively rich affair.

The agency model of communication has important implications for public health campaigns, because informing is heavily norm-bound and context-dependent. As Manson 
and O'Neill argue, acts of informing require a rich practical and normative framework to succeed. The meaning of what is communicated will depend on a shared understanding between participants in the act - the communicator and the audience - about what the context is, including actions, beliefs, and expectations. For example, if an audience mistrusts the communicator or assumes that she has violated certain norms of truth-telling, it may not accept the speaker's intended meaning; the act of information will fail because a communicator cannot inform a fundamentally mistrusting audience.

An important norm involved in communicating is that people interact on the assumption that communication is undertaken for reasons relevant to the participants, and, in particular, that there is a purpose to giving another person information (Manson and O'Neill 2007). Certainly, in the case of public health agencies, we assume that publicfocused communication is done for relevant public-focused reasons, and it is important that this belief is respected and upheld. Otherwise, the public may simply ignore the information delivered. The transparency of these reasons is another norm important to the act of communicating. Providing reasons, or being able to if asked, for communicating specific things demonstrates respect for persons through what Neil Manson (2010) terms "recognition respect"- recognizing each audience member as an agent with her own interests and the capacity to live her life as she sees fit. The failure to give audiencerelevant reasons for communicating something can indicate a lack of respect.

These norms of communication are underpinned by another: that information is rationally assessable and submitted to an audience as true (Manson and O'Neill 2007). In the everyday sense, information is bound to claims and proposals, which an audience must judge and react to (inwardly or outwardly). Audience members assume that communicators, especially organizations such as public health bodies, provide them with 
true information, which they can evaluate and determine to be relevant to themselves or put aside.

Crucial to a discussion of public health campaigns, Manson and O’Neill argue that informing is inferentially fertile; communication enables people to make a variety of inferences, and successful communication essentially depends on the use of inference by the audience to complete the transaction. They elaborate that communicative acts are made feasible thanks to the communicator's and audience's rich stocks of cognitive commitments, and that each assumes or knows that the other has and uses this stock, too. This interactive process explains how implicit messages (in anti-obesity campaigns, for example) can be utilized with some reliability. The communicator assumes that she and her audience share background knowledge about the world, and linguistic and social conventions that permit the use of such communicative tactics as plays-on-words, messages that hold multiple meanings, and stereotypes (Manson and O’Neill 2007). To deliver the intended messages, these strategies rely on an audience's ability to infer meanings from images and statements.

It is important to distinguish that Manson and O’Neill call the content of communicative interactions "information." However, "informing" is a particular kind of intentional communicative action, and it can take on various characteristics, which include the persuasive and the manipulative. As I explain below, persuading and manipulating share the intention behind communicating, but differ from each other based on the recognition-respect they exhibit toward the audience.

As mentioned above, we may assume that public health agencies often believe they are informing (or, they may say, educating) the public about a particular health-related issue. However, informing, in public health, is complex because the purpose behind 
informing on topics related to public health is usually to change a person's thinking or behavior, and sometimes both. This means that public health communication tends towards persuasion. However, while persuasion is sometimes considered morally problematic, it may be a kind of communication in which recognition-respect for the audience is maintained.

One is persuaded when one adopts a conclusion based on the merit of reasons presented by another person (Beauchamp and Childress 2001). On this definition, persuasion, as such, does not undermine an agency-based conception of communication; rather, the paradigmatic case of persuasion is a conversation between agents in which reasons for accepting a conclusion as true (or relevant) can be debated and evaluated. At one end of a spectrum of persuasion, we can find significant commonalities with a notion of educating: persuasion is something that we use regularly to teach each other about the world. In persuading a child not to touch a hot cooking surface, we employ elements of educating by presenting claims about the world ("I have been cooking, the surface is hot, and it will burn you"), but we do so with the intent of convincing the child that what we think should be done is the correct course of action ("You should not touch the thing that will burn you"). This will often fail, but that is beside the point. Persuasion is fundamentally social, is commonly used to exchange knowledge and lessons about the world, and, by its nature, requires discussion and engagement between agents. As such, a persuasive act of communication assumes the reciprocal respect and transparent intentions of participants. On such an understanding, persuasion may be morally permissible.

Importantly, the quality of the information presented to an audience - the claims about the world - made to persuade another to adopt a particular conclusion may be considered separately from the communicative act of persuasion. We may object to the 
content of a persuasive message, finding fault with the claims presented by another person for adopting a conclusion, while still accepting the process of persuasion itself. Persuasion is a respectful presentation of claims about the world with the intention of changing a person's mind or behavior in a particular way. If it is the case that public health is often persuading, then this process of informing is morally acceptable, and, in many cases, appropriate to public health's aims.

However, a large proportion of public health campaigns go further than persuasion in their quest to influence people's behaviors. In looking at anti-obesity campaigns, for example, one discovers that, while they may appear to share characteristics with persuading by making claims about the world that sound vaguely medically factual, they do not employ a communication style that engages respectfully with their audience. For example, the claim "obesity causes cancer" uses a complex understanding of the word "cause" that differs from the general sense of causation that a nonmedical audience could be relied on to employ, and, therefore, is not strictly true (McNaughton 2013). Rather, many of these campaigns seem to manipulate the audience into a conclusion via the generation of negative emotions and the employment of stereotypes.

Jennifer S. Blumenthal-Barby and Hadley Burroughs (2012) describe manipulation as a method of influence that bypasses a person's capacity for reason. This bypassing effect may happen by exploiting nonrational elements of human psychology or by subverting the rational decision-making process. Rather than present evaluable claims about the world, manipulative communication presents stereotypes or other components of stigmatization (Link and Phelan 2001) in visual or literal metaphor to evoke emotional responses, which bypass the audience's reasoning capacities. Manipulative messages often covertly contain cultural beliefs, aesthetic and moral judgments, and the value preferences of the 
communicator.

The boundary between persuasion and manipulation is not clear cut, and some campaigns may employ elements of both. However, there have been some anti-obesity campaigns that seem predominantly manipulative, many of which have been criticized in the media and by academics (e.g., Carter et al. 2015; Dailey 2012; Gollust et al. 2012; McNaughton 2013). Some features shared by such campaigns are that they portray people in ways that demonstrate a lack of respect, such as removing or hiding the faces of the individuals depicted (as in the "Cut Your Portions" posters), and they communicate stereotypes about fat people, such as implying that fat individuals lack self-control or are unhealthy, with the corollary that others must police their behavior.

Through what Manson and O’Neill (2007) call the "inferential fertility" of information, a lack of rationally evaluable claims and health-specific information in such campaigns does not prevent them from conveying their messages. In fact, the success of evoking feelings like guilt, anxiety about personal or parental failure, and shame relies on the inferences made by the audience through visual imagery and implications in the text. Manipulative communication assumes the audience's adherence to a range of communicative, epistemic, social, and ethical norms, as Manson and O’Neill described, but it fails to give the audience recognition-respect. In fact, manipulation denies the rational agency of the audience, while depending on its cognitive commitments to succeed.

Justifications for using manipulative tactics in public health campaigns have focused on the potential effectiveness of manipulation, especially when persuasive or informative communication appears ineffective. This is a fundamentally consequentialist 
position, which holds that as long as the results are positive (meaning that the public health campaign or policy creates better health outcomes) then the means by which this is achieved are justifiable. In this spirit, Blumenthal-Barby and Burroughs (2012) suggest that instances of manipulation, such as using guilt to motivate parents to make their children lose weight, can be justified "if a careful consideration shows that the benefits outweigh the risks," and if an explanation can be given for why manipulation rather than persuasion was used (7). However, certain harms, like contributing to the stigmatization of some groups, may never be ethically justifiable. Often, work in public health is guided by the conviction that health is highly valued and valuable, and is the most essential thing. This may not be as commonly held a conviction outside of health fields as it is inside them, and there may be some anti-obesity campaign messages that are impermissible based on the importance of values other than health. One of these values is justice, and such unintended side effects of obesity campaigns as stigmatization, shame, and the apparent prioritization of weightrelated health over other kinds of health (like mental health), contribute to injustice via oppression and undermining self-authorization.

\section{Oppression}

Manipulative anti-obesity campaigns contribute to the oppression of fat people. Here, I will limit myself to a discussion of two of Iris Marion Young's (1990) faces of oppression, and to the impingement on self-regarding attitudes required in one of the three axes of autonomy described by Catriona Mackenzie (2014).

Oppression is insidious, systemic, and embedded in everyday life. It designates what Young considered a family of concepts and conditions, which may entail or cause 
distributive injustice at the group level, but all of which involves issues of justice in addition to distribution. According to Young, many groups suffer from oppression of one form or another, or many forms at once. In addition, oppression, through its systemic nature,

refers to the vast and deep injustices some groups suffer as a consequence of often unconscious assumptions and reactions of well-meaning people in ordinary interactions, media, and cultural stereotypes, and structural features of bureaucratic hierarchies and market mechanisms - in short, the normal processes of everyday life. (41)

In this section, I argue that attitudes toward fatness - most conspicuously encapsulated in the term "obesity" - clearly meet the criteria for oppression described in Young's discussion of marginalization and cultural imperialism. While public health anti-obesity campaigns may not intend to oppress fat people, one result of engaging in manipulative ones is the reproduction of oppression.

First, Young describes marginalization largely in terms of labor relations. "Marginals," she says, are people the labor system either cannot or will not use. This, Young thinks, is perhaps the most dangerous form of oppression, because entire groups of people - the elderly, the disabled, certain racial groups, and, I argue, fat people - are excluded from useful and fulfilling social participation in the form of paid work. This means that they are potentially the victims of material deprivation, social exclusion, isolation, and the affective repercussions of these, such as low self-worth - an important self-regarding feeling for Mackenzie's (2014) concept of self-authorization. 
Young thinks that there are two primary injustices, beyond distribution, of marginalization in advanced capitalist societies: first, that provision of welfare creates further injustices by depriving beneficiaries of freedoms and rights, and, second, that it blocks the opportunity for exercising capacities in socially defined and recognized ways (53-54). Because of its relevance for self-authorization, I will focus on the second injustice of marginalization. Young says that even if, through the provisions of a welfare state, marginalized people were materially comfortable, injustices would remain "in the form of uselessness, boredom, and lack of self-respect" (55). Most of society's productive and recognized activities take place in contexts of organized social cooperation, such as employment and education, and to be excluded from these involves unjust deprivation of cultural and practical opportunities for exercising capacities, being recognized as a person, and interacting with others.

Confirming Young's hypothesis, social scientists have found that fat people are less likely to be hired, less likely to be promoted, more likely to be paid less than their slim colleagues, more likely to be terminated without cause, and are subject to stereotypes and discriminatory assumptions in the workplace: that they are less intelligent, less motivated, less ambitious, and less effective employees (Puhl and Heuer 2009; Puhl and Heuer 2010). Through the covert workings of stereotype and bias, fat people are more likely to lose their jobs, and less likely to get hired for new positions. The process of marginalization has even translated into voyeuristic newspaper stories and reality television shows focusing on people who are "too fat to work."

Public health anti-obesity campaigns feed into the stereotypes in play in employment decisions. Through the complex interpretive move in which we connect outward appearance and behavior to internal states, campaigns use visual cues to indicate 
dispositional attitudes and health status (Messaris and Abraham 2001). Public health campaigns call on - or count on (Abu-Odeh 2014) - the audience's pre-established stereotypes to activate negative judgments and feelings. In a video campaign focused on the consumption of sugary beverages entitled "Do You Drink 93 Packets of Sugar a Day? (NYC DOH MH 2011), a person - meant to be a signifier of oneself if one is fat, but also representing potential employees or colleagues - is seen at various points in his workday drinking large sugary beverages and then, at home, eating a meal of take-out food and soda. The message of the video is, first, that drinking such beverages is unhealthy and, second, that the employee who drinks them is unhealthy, lazy, and not how people ought to be. The messages that public health agencies communicate in such campaigns, and the stereotypes they call upon to deliver their messages, transpose erstwhile health matters into the other areas of people's lives. This has had a clear impact on employment opportunities for fat people as weight-related biases contribute to their marginalization.

Second, on Young's definition, cultural imperialism involves the establishment of a "normal" set of experiences, goals, and culture through the universalization of the dominant group's views. To experience cultural imperialism, Young says, is to "experience how the dominant meanings of a society render the particular perspective of one's own group invisible at the same time as they stereotype one's group and mark it out as the Other" (5859). I hesitate to suggest that fat people experience a group identity in the sense that this definition might imply (though this could be changing in parts of the fat acceptance movement). However, I think both processes of "making invisible" and "Othering" are at work in cultural attitudes toward fat. A fat person's perspective on herself and her life is made invisible insofar as she is subjected to the definitions of dominant culture - of illness, inability, unattractiveness, and so on. At the same time, fat people are Othered, stereotyped, 
and even presented in popular media as threats or enemies. Young's further explication of cultural imperialism certainly seems applicable to fat people: she says that the culturally imperialized become "remarkable, deviant beings" who are stamped with an essence. This "[confines] them to a nature which is often attached in some way to their bodies, and which thus cannot easily be denied" (59).

Like Erving Goffman's (1963) explanation of the discrediting attributes in stigma, Young locates cultural imperialism in aspects of one's body; the culturally imperialized are obvious and visually-detected outsiders, their social interactions foregrounded by stereotype. So, one's identity is created for one by the dominant group's meanings. Through the creation of "ugly bodies," marking out the culturally imperialized as "dirty, defiled, impure, contaminated, or sick," the dominant group exercises its powers of Othering and standardization (Young 1990, 123). The dominant view stands as normal, rational, and objective, and the dominant group can harness science to enforce and reinforce the categories created in cultural imperialism. As the privileged groups lose their peculiarity, assuming the position of a universal, scientific view, the oppressed become "locked in their objectified bodies" (127). While the culturally imperialized are denied the opportunity to define themselves, and are marked as degenerate, flawed, and undesirable, the dominant group is allowed to individuate and takes the position of superiority, bodily and morally.

Culturally imperialized people internalize the dominant group's views, says Young, at least to the extent to which they are forced to react to them. Young argues that this creates what W.E.B. Du Bois ([1903] 1969) called "double consciousness": "the sense of always looking at one's self through the eyes of others, of measuring one's soul by the tape of a world that looks on in amused contempt and pity" (quoted in Young 1990, 60). While 
the subject sees herself as a person capable of achieving her goals and living a life of hope and possibility, the dominant culture tells her that she is flawed, inferior, and incapable.

Through exercising their dominant-group claims on scientific objectivity, public health agencies culturally imperialize groups of people under the auspices of promoting health. The decision that "health," in general, or that the particular notion of health-asthinness should be promoted is rooted in value judgments. Decisions to transform human differences into medical problems (the process of medicalization) and about how much and what kind of health risk should be tolerated are also rooted in values. The values providing the basis for these decisions are those held by the dominant group, and such processes as medicalization help the dominant group to mark out the Other and reinforce categories of difference.

All of this happens on a structural level; I do not wish to suggest that any particular public health researcher or practitioner sets out to oppress others through marking them as different. However, processes of oppression are at play in public health anti-obesity (and other) campaigns, and health and scientific concerns surrounding fat are not free from oppression based in marginalization and cultural imperialism. This injustice is sufficient to render public health anti-obesity campaigns unethical. However, the impact that these campaigns have upon the self-authorization of the intended audience is important to consider and is tied to the reproduction of oppression.

\section{Autonomy}

Catriona Mackenzie's recent work (2014) presents self-determination, self-governance, and self-authorization as three distinct but crucially interconnected axes of autonomy. These categories of capabilities and attitudes allow us to think with greater specificity than does 
the umbrella term "autonomy" about the many ways in which competence for self-directed living is undermined or fostered. Mackenzie thinks that we must continue to use the term “autonomy," but I worry that continuing its use (at best) allows us to forget all the work she has done to elaborate the concept's complexity or (at worst) to ignore it. I realize that this is controversial, but I will resist the urge to use autonomy as shorthand for particular sets of conditions internal or external to an agent. Whether we keep using autonomy or not, I think that each of Mackenzie's three axes can be utilized to see how the capacities for selfdirected decisions are undermined by particular, cultural, and structural conditions, including manipulation in public health campaigns.

Mackenzie describes self-authorization as composed of self-regarding attitudes internal to the individual, while self-governance is composed of skills and agency (a combination of internal and external factors), and self-determination is composed of structural and justice conditions external to the individual. In the interests of space, I will focus on the impact that manipulation has on important components of self-regard and, thus, will focus largely on the axis of self-authorization. In contributing to oppression experienced by fat people, manipulative health messages undermine the development or exercise of self-trust and self-worth required for self-authorization; oppression makes people feel that they are less worthy and less competent (Carter et al. 2015; McLeod and Sherwin 2000). I will discuss self-trust, self-worth, and body image separately as selfregarding attitudes that are important to self-authorization and impinged by manipulative public health campaigns. That said, self-authorization, self-governance, and selfdetermination have significant interplay, and manipulation leaves none of them untouched.

\section{a. Self-Trust}


Carolyn McLeod (2002) argues that two components of trust are important to both interpersonal and reflexive attitudes: optimism regarding competence and moral integrity (36). Self-trust is socially constituted; it is moulded to a significant degree by the responses of others toward us and by societal norms (37). One has to think, and feel internally, that one is competent to make certain kinds of choices in order for one to trust oneself to do so. To gain the attitude that one is competent at something, rather than just possessing the skill set constituting competence, one must have some amount of positive (or, at least, not an abundance of negative) reinforcement from others. In cases of oppression, this may be missing from one's milieu.

McLeod argues that rather than requiring a list of necessary and sufficient conditions to determine what trust is or who is trustworthy, people utilize prototypical concepts. A "prototype," an idea from cognitive science, is a "kind of artificial exemplar that combines the statistically most salient features of exemplars of the same class to which the subject has been exposed" (13). This approach to trust, and to other philosophical concepts, appeals insofar as, in day-to-day life, one rarely reasons from a list of necessary and sufficient conditions. Rather, we expand our existing concepts to meet experience. However, the source of our prototypes is a political question, as socially dominant groups, through cultural imperialism, create and represent prototypes of many virtues trustworthiness, beauty, success, intelligence, responsibility, achievement, and so on - as parts of their privilege.

Thus, McLeod argues that one barrier to knowing oneself and to trusting oneself well is the distortion of one's prototype for trust by oppressive stereotypes (75). For example, if the prototype of a trustworthy individual is depicted as being thin, selfcontrolled, and professional, among other characteristics (which might include maleness, 
whiteness, heterosexuality, and other things) then the ways in which one differs from this prototype will challenge one's sense of trustworthiness. One's prototype will stretch to fit new cases where important similarities exist - some features of a prototype will be more salient than others - so one may have some differences from the prototype and still see oneself as trustworthy. But sometimes people will be told that they are different in significant ways from the prototype, and, thus, do not fit the description. In manipulative anti-obesity campaigns, for example, fat people are depicted in ways that suggest that they ought not to trust themselves, because they differ significantly from the prototype of trustworthiness. To illustrate, public health messages that imply to a fat person that most of the time she makes "inappropriate" or wrong food choices may undermine her attitude that she can be trusted to choose responsibly. In these campaigns, fat people are rarely depicted as self-controlled or professional; rather, they tend to be stereotypically portrayed as falling prey to cravings or inattentive consumption, and are never (to my knowledge) portrayed in professional roles or attire. These messages tell fat people that they do not match with the prototype of trustworthiness and, thus, undermine their feelings of self-trust.

So, McLeod says that "oppressive trust prototypes often encourage people who are oppressed to distrust themselves where self-trust is warranted, and to trust others who neither have their best interests at heart nor the knowledge to be able to say with authority what their best interests are" (76). Public health anti-obesity campaigns provide an interesting case for this claim, because we could admit that public health agencies do see themselves as acting in ways that have the public qua individuals' best interests at heart, and that they do operate as if they have knowledge of what those interests are. We could also recognize, however, that public health agencies may misinterpret the best interests of some groups some of the time, or choose means for meeting these interests that perpetuate 
oppression, albeit unintentionally. Manipulative anti-obesity campaigns are one such case of misapplied public health interventions.

\section{b. Self-worth}

Mackenzie (2014) says that a sense of worthiness is also important for self-authorization. This is important as both a sense of worthiness of being trusted and as moral integrity. According to Paul Benson (2000), moral integrity concerns one's worthiness to be responsible: to be worthy of giving account of one's actions to others (81). An attitude of moral responsibility supposes that one is worthy of a certain social standing, and is a kind of social recognition (79). Being responsible is a reciprocal position; one can be responsible and be held responsible, and can hold others responsible in turn (78). To hold or be held responsible is a position among people of equal worthiness to account for their actions; if one is at a higher or lower social position than another, one will either feel no responsibility to account for oneself, or lack the ability to do so, respectively.

Since we know that not everyone in a society is considered equal, or is afforded equal recognition and social standing, Benson says that people's sense that they have lost (or perhaps never had) full standing in the moral community "will bring a change in their attitude toward their worthiness to disclose values and commitments to others through actions" (78). Benson postulates that people may not feel self-worth sufficient for responsibility partly because "any efforts they might make to speak for their own actions would be perceived as transgressing established demarcations of social status, and so would simply not count morally" (80). Being held responsible for one's actions or beliefs implies that one is considered equal and that one's reasons for doing actions or holding beliefs could be accepted as reasons, even if they were disputed. In order to dispute, one must recognize one's opponent to be worthy. 
This idea evokes the foregoing definition of persuasion, where agents are addressed in a mutually respectful conversational format as two parties to an exchange of ideas. A similar context is implied in holding and being held responsible; thus, if one party is not considered fit to account for herself, there can be no exchange of ideas, and, therefore, no position of responsibility for one's actions or beliefs. So, a person who realizes that she is not afforded the same standing as others may feel a lack of worth, and this could gain expression through that person's self-regarding attitude that her values are not worthy of disclosure, or her commitments not the correct ones on which to act.

Further, it seems that even if one thinks that one could account for oneself, if others do not afford one the recognition required for responsibility, one's justifications for one's beliefs or actions may not be considered justifications at all. If one is held by the broader society to be unequal, as fat people are held, then the sorts of reasons one could provide for one's actions may simply be disregarded as wrong or misguided, and, thus, not stand as acceptable reasons at all. Fat people may, in addition, be considered by privileged social groups as "incapable of the kinds of moral sensitivity, reasoning, and self-control that would warrant their recognition as fully accountable agents" (Benson 2000, 80). For people who have internalized the prevailing norms of such a society, an attitude of low self-worth "will be one element of the broader lack of moral self-respect, the failure to recognize their fundamentally equal moral worth as persons" (80). This, both Benson and McLeod (2002) agree, may lead people to have grave doubts about their own competence as moral agents and self-authorizing actors.

\section{c. Body Image}

Finally, campaign posters or videos that attack certain kinds of bodies by displaying them as undesirable or ill may undercut feelings of self-esteem based on body image. Since our 
sense of self-worth, self-trust, and other self-regarding attitudes are shaped socially by what others think and say about us, we perceive how others see us through the way we are treated, and through how others that we think are like us are treated or depicted in various media (McLeod and Sherwin 2000). Depictions of people who we perceive to be like us in flattering or unflattering ways will inform our self-conception and our sense of the social positions we occupy. Thus, public health anti-obesity campaigns that show fat people in stereotypical or stigmatizing contexts may lead others to perceive their own worth and status as less than people who "accurately" express certain prototypical concepts, whether that is "healthy," "trustworthy," "responsible," "successful," or others.

Many anti-obesity campaigns employ stereotype or stigma to make people feel bad about their bodies or behaviors in order to encourage change. The assumption that it is acceptable to make people feel bad as motivation to make them change their behaviors is deeply problematic. Fat people are constantly told that there is something wrong with them, without consideration for how this impacts their self-regard or on the assumption that something about their self-regard is defective. Thus, fat people report on encounters with colleagues, friends, and complete strangers that "whilst their bodies were highly visible their thoughts and feelings were completely invisible to others" (Lewis et al. 2011, 1352). In the examples I provided in the introduction to this essay, one woman is depicted as if she is laboring to climb stairs, and another is depicted as requiring mobility assistance. Both of these images seem to show the physical limitations of fat bodies (though, as discussed, the woman on the stairs may be defying the stereotype the image is attempting to employ). The image of the woman on the mobility scooter implies illness and disability. Without any further explanation or context, the images tell the audience that these women are suffering as a result of the fat on their bodies. For people who see the women in these images as 
similar to themselves, one of the effects they engender is a feeling of shame. In the philosophy of emotions, feelings of guilt are associated with actions, while feelings of shame are associated with our nature; something discloses a flaw in who we are when we feel shame (McLeod 2002, 43). Natalie Stoljar (2000) thinks that shame is the result of a sense of failing to live up to the norms that people take as applicable to them (109). Shame seems intended in these campaigns - certainly many people balk at the idea that fat people would be proud of their bodies, in part because fat is currently so conceptually connected with illness and moral failing (McNaughton 2013). However, feelings of shame cannot be compatible with self-authorization in a long-term sense. Self-authorization, including selfregarding attitudes of trust and worth, could perhaps withstand momentary feelings of shame, but when shame becomes an everyday position because of a deluge of messages from the broader society that one is somehow deeply lacking in one's very nature, the selfregarding feelings that make self-authorization possible may be drastically impeded. This means that public health campaigns that attempt to motivate new behaviors by engendering feelings of shame are both unethical and self-defeating.

Moreover, when seen from the level of population rates of obesity, all fat people are equally problematic. However, the messages in public health campaigns and the images that are chosen to accompany them betray deep gender biases. There is a tendency to target (cis)women in these campaigns as mothers, food providers, and primary caretakers of the family. For example, in "Me Sized Meals" (National Health Service England [NHS] 2009), a video that is part of the NHS-sponsored "Change 4 Life" campaign, the first line is "Mum loves me." The (featureless plasticine) child in the video explains that his mother feeds him too much, and that he needs his mum to provide "me-sized meals" to prevent overeating. A proper analysis of the ethical implications of this video, and many like it that feature 
mothers or are directed toward mothers ${ }^{2}$, would require its own article. The scrutiny of mothers' bodies and behaviors as sites of obesity prevention is ever-increasing. Women are pressured to breastfeed; their weights before, during, and after pregnancy are closely monitored; and increasing research into maternal epigenetic contributors to childhood levels of body fat is placing mothers under intense surveillance (Bell et al. 2009; Dablea and Crume 2011; Heerwagen et al. 2010).

The negative body-image effects of public health campaigns may also be greater among women than men. Body fat has a deeply gendered meaning (Bordo 2003; Harris et al.1991; Lewis et al. 2011; McPhail and Bombak 2015), and fat women and fat men face different stereotypes and occupy different social spaces (Harris et al. 1991). Research into stereotypes about fat people has found that stereotypes of fat women are significantly more negative than those of fat men. Accordingly, "women are both more concerned about their weight and more likely to be judged on their appearance than men" (Harris et al. 1991, 1562). That said, fat men's gender identity may be threatened by the social meanings of fat. Susan Bordo (2003) writes that "soft, protuberant body parts... evoke helpless infancy and symbolize maternal femininity" (208). Thus, body fat that gives the appearance of breasts or large hips may have "a 'feminizing characteristic' that has significant implications for [men’s] gender identity" (McPhail and Bombak 2015, 541). However, Deborah McPhail and Andrea Bombak (2015) write that while fat may be feminizing for men (including trans men), it is paradoxically masculinizing for women. Fat women take up physical space that is typically reserved for men, while the "undesirability" of their bodies removes them from stereotypical heterosexual gender roles and renders their bodies asexual.

McPhail and Bombak argue that lesbian communities are problematic from public health's perspective because, through rejecting traditional gender and sexual identity 
expectations, these groups tend toward fat positivity, and, therefore, public health considers them in need of intervention. Through public health's efforts, however, fat as "illness" contributes to a recoding of lesbianism as "sick" (McPhail and Bombak 2015, 542). Sexual minority women, they write, are thus targeted as populations that are particularly "at risk" for obesity, and are further marginalized. While I cannot do justice here to the important criticisms of public health messages that come from critical gender and fat studies, it should be made clear that the political, gendered, and body-situated meanings in public health antiobesity campaigns are problematic for straight and queer communities of women, albeit in different ways. One important commonality, however, is the undermining of feelings of self-worth, and the fostering of feelings of shame and self-doubt, which are incompatible with self-authorization.

\section{Conclusion}

With critical self-regarding attitudes undermined through public health anti-obesity campaigns (and the broader workings of society), self-authorization is dramatically reduced. Even if it were not the case that self-governance and self-determination are also undermined by these campaigns - and it would be hard to imagine how this could be so, given that oppression is incompatible with the justice structures necessary to selfdetermination (Mackenzie 2014) - the impact of these campaigns on self-authorization may make it virtually impossible for people to take the kind of self-directed actions regarding their health that public health advocates. Public health recommends that people make various changes, which require a high degree of self-efficacy, and the campaigns public health uses to send these messages undermine that self-efficacy. 
In sum, public health anti-obesity campaigns contribute to systems of injustice by enacting modes of oppression and undermining the attitudes necessary for self-authorized decision making. Because of this, they limit people's abilities to make the kinds of changes to behavior that they recommend. These campaigns are, thus, not only deeply unethical, but they are ultimately self-defeating. If public health agencies desire behavior change, then they must treat the people in their target audience as responsible and effective moral agents, which, in turn, requires public health to engage in a manner that permits respectful conversation and debate about health-related (and other) values.

\section{ACKNOWLEDGMENTS}

A short version of this paper was presented at the meeting of the International Network on Feminist Approaches to Bioethics (FAB) held in Edinburgh in June 2016. I appreciate having had the opportunity to share my ideas in that space, and the helpful input from FAB attendees. I would like to thank Angus Dawson for his support and constructive feedback, as well as IJFAB's two anonymous reviewers, whose comments improved this paper in a number of ways. Funding in support of this project was provided by a Wellcome Trust Fellowship, WT104894MA.

\section{NOTE}

1. Benefits Britain: Life on the Dole (2014), a U.K. television show, provides a particularly good illustration of the harmful effects of marginalization, including scrutiny by others and humiliation.

2. "The Talk: Mom and Dad," (n.d) a video that was formerly included as part of Children's Healthcare of Atlanta's Strong4Life campaign, provides another 
example of how (cis)women are targeted as mothers and food providers. Among other things, the video presents many gendered messages about parenting, food provision, and food preparation, layered over messages about fatness. While it tells the viewer that parents need to be a team to help their families eat healthier, it also plays on heteronormative and gender stereotypes commonly found on American television: dad is an easygoing junk food lover, while mom is a health conscious worrier. There are also apparent class implications, as the house depicted in the video is quite large, and the parents are portrayed as having a significant amount of choice about what to eat. This may be at odds with the lives of people who were targeted by this campaign. ("The Talk: Mom and Dad" is no longer available online; it has recently been removed from the list of videos on Strong4Life.com and from Children's Healthcare of Atlanta's YouTube channel.)

\section{REFERENCES}

Abu-Odeh, Desiree. 2014. "Fat Stigma and Public Health: A Theoretical Framework and Ethical Analysis.” Kennedy Institute of Ethics Journal 24 (3): 247-65.

Beauchamp, Tom L., and James F. Childress. 2001. Principles of Biomedical Ethics. 5th ed. Oxford: Oxford University Press.

Bell, Kirsten, Darlene McNaughton, and Amy Salmon. 2009. "Medicine, Morality and Mothering: Public Health Discourses on Foetal Alcohol Exposure, Smoking around Children and Childhood Overnutrition." Critical Public Health 19 (2): 155-70.

Benefits Britain: Life on the Dole. 2014. Channel 5, Viacom International Media Networks Europe. http://www.channel5.com/show/benefits-britain-life-on-the-dole 
Benson, Paul. 2000. "Feeling Crazy: Self-Worth and the Social Character of Responsibility." In Relational Autonomy: Feminist Perspectives on Autonomy, Agency, and the Social Self, ed. Catriona Mackenzie and Natalie Stoljar, 72-93. Oxford: Oxford University Press.

Blumenthal-Barby, Jennifer S., and Hadley Burroughs. 2012. "Seeking Better Health Care Outcomes: The Ethics of Using the 'Nudge.'” American Journal of Bioethics 12 (2): $1-10$.

Bordo, Susan. 2003. Unbearable Weight: Feminism, Western Culture, and the Body. 2n ed. Berkeley: University of California Press.

Carter, Stacey M., Vikki A. Entwistle, and Myles Little. 2015. "Relational Conceptions of Paternalism: A Way to Rebut Nanny-State Accusations and Evaluate Public Health Interventions." Public Health 129 (8): 1021-29.

Children's Healthcare of Atlanta. n.d. http://www.strong4life.com

National Health Service, England (NHS). 2009. “Change4Life 'Me Sized Meals.” 2009. YouTube video, April 3. https://www.youtube.com/watch?v=kfCC3Sjz8Dk

Dabelea, Dana, and Tessa Crume. 2011. "Maternal Environment and the Transgenerational Cycle of Obesity and Diabetes." Diabetes 60 (7): 1849-55.

Dailey, Kate. 2012. “Atlanta Anti-Obesity Ads 'Risk Child Stigma.” BBC News, February 9. http://www.bbc.com/news/world-us-canada-16958865

Du Bois, W.E.B. (1903) 1969. The Souls of Black Folk. New York: New American Library. Goffman, Erving. 1963. Stigma: Notes on the Management of Spoiled Identity. New York: Simon \& Shuster. 
Gollust, Sarah E., Ijeoma Eboh, and Colleen L. Barry. 2012. "Picturing Obesity: Analyzing the Social Epidemiology of Obesity Conveyed through US News Media Images." Social Science \& Medicine 74 (10): 1544-51.

Harris, Mary B., Laurie C. Walters, and Stephanie Waschull. 1991. "Gender and Ethnic Differences in Obesity-Related Behaviors and Attitudes in a College Sample.” Journal of Applied Social Psychology 21 (19): 1545-66.

Heerwagen, Margaret J.R., Melissa R. Miller, Linda A. Barbour, et al. 2010. "Maternal Obesity and Fetal Metabolic Programming: a Fertile Epigenetic Soil.” American Journal of Physiology-Regulatory, Integrative and Comparative Physiology 299 (3): R711-22.

Heuer, Chelsea A., Kimberley L. McClure, and Rebecca M. Puhl. 2011. “Obesity Stigma in Online News: A Visual Content Analysis." Journal of Health Communication 16 (9): 976-87.

Lewis, Sophie, Samantha L. Thomas, R. Warwick Blood, et al. 2011. "How Do Obese Individuals Perceive and Respond to the Different Types of Obesity Stigma That They Encounter in Their Daily Lives? A Qualitative Study." Social Science \& Medicine 73 (9): 1349-56.

Link, Bruce G., and Jo C. Phelan. 2001. “Conceptualizing Stigma.” Annual Review of Sociology 27 (6): 363-85.

Mackenzie, Catriona. 2014. “Three Dimensions of Autonomy: A Relational Analysis.” In Autonomy, Oppression, and Gender, ed. Andrea Veltman and Mark Piper, 15-41. Oxford: Oxford University Press.

Manson, Neil C. 2010. "Why Do Patients Want Information If Not to Make Decisions?" Journal of Medical Ethics 36 (12): 834-37. 
Manson, Neil C., and Onora O'Neill. 2007. Rethinking Informed Consent in Bioethics. Cambridge, UK: Cambridge University Press.

McLeod, Carolyn. 2002. Self-Trust and Reproductive Autonomy. Cambridge, MA: MIT Press.

McLeod, Carolyn, and Susan Sherwin. 2000. "Relational Autonomy, Self-Trust, and Health Care for Patients who are Oppressed." In Relational Autonomy: Feminist Perspectives on Autonomy, Agency, and the Social Self, ed. Catriona Mackenzie and Natalie Stoljar, 259-79. Oxford: Oxford University Press.

McNaughton, Darlene. 2013. “'Diabesity’ Down Under: Overweight and Obesity as Cultural Signifiers for Type 2 Diabetes Mellitus." Critical Public Health 23 (3): 274-88.

McPhail, Deborah, and Andrea E. Bombak. 2015. "Fat, Queer and Sick? A Critical Analysis of 'Lesbian Obesity' in Public Health Discourse.” Critical Public Health, 25 (5): 539-53.

Messaris, Paul, and Linus Abraham. 2001. "The Role of Images in Framing News Stories." In Framing Public Life: Perspectives on Media and Our Understanding of the Social World, ed. Stephen D. Reese, Oscar H. Gandy, Jr., and August E. Grant, 21526. New York: Routledge.

National Health Service England (NHS). 2009. "Change4Life 'Me Sized Meals."” YouTube video, April 3. https://www.youtube.com/watch?v=kfCC3Sjz8Dk

New York City Department of Health and Mental Hygiene (NYC DOH MH) 2011. "Do You Drink 93 Sugar Packets a Day?” YouTube video, January 31. https://www.youtube.com/watch?v=hF8XnU4L33U 
New York City Department of Health and Mental Hygiene (NYC DOH MH). 2012. “Cut Your Portions, Cut Your Risk." http://www1.nyc.gov/assets/doh/downloads/pdf/cdp/portion-campaign-ads.pdf

Puhl, Rebecca M., and Chelsea A. Heuer. 2009. "The Stigma of Obesity: A Review and Update." Obesity 17 (5): 941-64.

Puhl, Rebecca M., and Chelsea A. Heuer. 2010. “Obesity Stigma: Important Considerations for Public Health.” American Journal of Public Health 100 (6): 1019-28.

Stoljar, Natalie. 2000. "Autonomy and the Feminist Intuition.” In Relational Autonomy: Feminist Perspectives on Autonomy, Agency, and the Social Self, ed. Catriona Mackenzie and Natalie Stoljar, 94-111. Oxford: Oxford University Press.

Young, Iris Marion. 1990. Justice and the Politics of Difference. Princeton, NJ: Princeton University Press.

\section{CONTRIBUTOR INFORMATION:}

Kathryn MacKay is a doctoral candidate at the University of Birmingham in Edgbaston, Birmingham, UK, and currently focusing on ethical and social justice considerations in public health endeavors, as well as the social justice ramifications of the political uptake of behavioral sciences research. Her areas of interest include feminist theory, moral philosophy, and political philosophy. 